\title{
O DESENVOLVIMENTO LOCAL E A SUSTENTABILIDADE DA ASSOCIAÇÃO DE CATADORES DE MATERIAIS RECICLÁVEIS DE COLOMBO (RESOL)
}

\author{
LOCAL DEVELOPMENT AND THE SUSTAINABILITY OF THE \\ ASSOCIATION OF RECYCLABLE WASTE COLLECTORS IN COLOMBO
}

\author{
Elgson Decarle de Oliveira ${ }^{1}$ \\ Eloy F. Casagrande Jr. ${ }^{2}$
}

\section{RESUMO}

Este artigo aborda alguns trabalhos realizados pela Associação de Catadores de Materiais Recicláveis de Colombo (RESOL) quanto ao desenvolvimento local para a geração de trabalho e renda. A partir de um novo cenário gerado por um projeto de apoio aos empreendimentos organizados em Associações e Cooperativas de Catadores, oriundo de políticas públicas do governo federal para o incentivo à reciclagem de resíduos, por meio da Fundação Nacional de Saúde (FUNASA), foram realizados investimentos em infraestrutura na RESOL. O objetivo deste trabalho foi identificar e analisar o aumento de renda e postos de trabalho na RESOL a partir dos novos recursos. Trata-se de um estudo desenvolvido por metodologia qualitativa, com aplicação de entrevista semiestruturada e observação em campo durante três anos, corroborando na confirmação dos resultados. Após a implementação dos novos recursos ocorreu: aumento de $285 \%$ na renda dos associados, aumento de $80 \%$ na geração de novos postos de trabalho e evolução de $276,80 \%$ na quantidade de material reciclado, e que, portanto, não foi descartado em lixões a céu aberto e aterros sanitários. $O$ investimento público propiciou melhoria na efetividade administrativa e operacional do Empreendimento de Economia Solidária representada pela Associação de Catadores, e tais resultados podem fortalecer o processo de sustentabilidade socioeconômica e ambiental da comunidade local.

Palavras-chave: Sustentabilidade Socioeconômica e Ambiental; Desenvolvimento Local; Políticas Públicas.

\begin{abstract}
This article deals with some studies conducted by the Association of Recyclable Waste Collectors in Colombo (RESOL) concerning local development to generate work and income. A new scenario generated by a project that supports organized ventures in Associations and Cooperatives of Waste Collectors in the wake of public policies of the federal government that encourage the recycling of residues through the National Health Foundation, investments were made in the RESOL. The aim of this work is to identify and analyze the rising income and number of workplaces at RESOL as a result of the new resources. It is a qualitative study. Data were gathered through a semi-structured interview and field studies over a period of three years to corroborate the results. In the wake of the implementation of new resources, the income of the members of RESOL rose by $285 \%$. There was an $80 \%$ rise in the number of workplaces and the quality of the recycled material rose by $276.80 \%$. Therefore, this waste was not dumped in landfills or rubbish tips. This public investment led to a wellmanaged and operated venture in economic solidarity for the members of the association. These results may strengthen the process of socio-economic and environmental sustainability of the local community.
\end{abstract}

Key words: Socio-economic and Environmental Sustainability; Local Development; Public Policy.

1 Mestre do Programa de Pós-Graduação em Tecnologia da Universidade Tecnológica Federal do Paraná (UTFPR), Professor do Curso de Administração da UNIBRASIL. E-mail: elgson.dec@ gmail.com

$2 \mathrm{PhD}$ em Engenharia de Recursos Minerais e Meio Ambiente pela Universidade de Nottingham, Inglaterra, Professor da Universidade Tecnológica Federal do Paraná (UTFPR). E-mail: eloy.casagrande@ gmail.com 


\section{Introdução}

Este trabalho apresenta um estudo de caso feito na Associação de Catadores de Materiais Recicláveis (RESOL), localizada no município de Colombo/PR, em uma região de vulnerabilidade social e de baixo Índice de Desenvolvimento Humano (IDH). Foi desenvolvido um projeto de convênio entre a RESOL e a Fundação Nacional de Saúde (FUNASA), que proporcionou investimentos em infraestrutura (equipamentos e caminhão), a partir de recursos disponibilizados por políticas públicas voltadas ao desenvolvimento local de Associações de Catadores na geração de trabalho e renda.

Neste artigo, foram selecionados conteúdos do Projeto e do cenário que compõem a RESOL para analisar os resultados práticos impactados pelos novos investimentos, que podem influenciar no processo de sustentabilidade socioeconômica e ambiental na comunidade local.

A sustentabilidade socioambiental ocorre quando ações sistêmicas são capazes de transformar modelos tecnoeconômicos cartesianos em resoluções que promovam real qualidade de vida às atuais e futuras gerações, respeitando nossas diversidades culturais e potencializando nossas características regionais. Ambiente saudável é um direito de todos, assim como o acesso a renda, saúde, habitação, educação e lazer. (CASAGRANDE JUNIOR, 2001).

A sustentabilidade ambiental está relacionada ao reaproveitamento dos resíduos sólidos por meio da reciclagem, que impacta no processo produtivo, quando toneladas de resíduos deixam de ser descartados em aterros sanitários, voltando a ter função no ciclo de vida do produto. Consequentemente, a vida útil desses aterros é prolongada, há menos poluição de materiais descartados na natureza, economia de recursos materiais "in natura" que compõem o produto acabado e economia de recursos naturais, como energia e água. Os mercados da reciclagem de resíduos sólidos que têm mostrado certo crescimento são: papel, plásticos, vidro, PET, embalagens longa vida, latas de alumínio e aço (CEMPRE, 2013).

Agregado ao viés ambiental está o processo de sustentabilidade socioeconômica, representado pela geração de trabalho e renda para os catadores associados, atores deste estudo. A partir desta matéria-prima composta pelos recicláveis, é fomentado o desenvolvimento local da comunidade em que a RESOL está inserida. As políticas públicas do governo federal de apoio aos empreendimentos associativos de catadores fortaleceram a Associação quanto aos quesitos de estruturação produtiva e logística na atividade de coleta e triagem dos materiais recicláveis, recebidos de organizações públicas e privadas, além do material da coleta seletiva disponibilizado pela prefeitura.

Para Guareschi et. al. (2004, p. 180), política pública é: 
o conjunto de ações coletivas voltadas para a garantia dos direitos sociais, configurando um compromisso público que visa dar conta de determinada demanda, em diversas áreas. Expressa a transformação daquilo que é no âmbito privado em ações coletivas no espaço público.

Neste estudo, entende-se que a sustentabilidade implica, em inter-relação de justiça social, qualidade de vida, equilíbrio ambiental e a ruptura com o atual padrão de desenvolvimento (JACOBI, 1997). Nesse sentido, este projeto foi desenvolvido para oportunizar à população dessa área comunitária menos favorecida, influenciada pela vulnerabilidade social (desemprego, miséria, drogas, mendicância e furtos), a possibilidade de inserção social mediante o trabalho gerado na RESOL, por meio da atividade de coleta, triagem e comercialização dos materiais recicláveis. A Constituição Federal de 1988 dá poder a esse Projeto e estabelece, em seu artigo 193: “A ordem social tem como base o primado do Trabalho, e como objetivo o bem-estar e justiça sociais". Fundamenta-se no artigo 170: "a ordem econômica, fundada na valorização do trabalho humano e na livre iniciativa, tem por fim assegurar a todos existência digna, conforme os ditames da justiça social, observado o princípio VIII que estabelece a busca do pleno emprego". Amparada pelo artigo $3^{\circ}$ : "constituem objetivos fundamentais da República Federativa do Brasil: I. construir uma sociedade livre, justa e solidária; II. Garantir o desenvolvimento nacional; III. Erradicar a pobreza e a marginalização e reduzir as desigualdades sociais e regionais" (BRASIL, 1988).

Conforme aponta Razzoto (2009), pode-se definir que "desenvolvimento sustentável" é desenvolvimento continuado. Na concepção de Amartya Sen, economista indiano e Prêmio Nobel de economia de 1988:

Só há desenvolvimento quando os benefícios do crescimento servem à ampliação das capacidades humanas, entendidas como o conjunto das possibilidades que podem ser alcançadas, aquilo que uma pessoa pode ser ou fazer na vida. São quatro as mais elementares: ter uma vida longa e saudável, ser instruído, ter acesso aos recursos necessários para um nível de vida digno e ser capaz de participar da vida da comunidade. (SEN, 1999).

\section{Materiais e métodos}

A metodologia utilizada foi a pesquisa qualitativa, por meio de entrevista, utilizando um roteiro semiestruturado que abordava questões referente a RESOL.

Segundo Godoy (1995), a pesquisa qualitativa não procura enumerar os eventos estudados, nem emprega instrumental estatístico na análise dos dados. 
A pesquisa tem o ambiente natural como fonte direta de dados e o pesquisador como relevante; é descritiva; o significado que as pessoas dão às coisas e a si mesmas é a preocupação essencial do investigador; os pesquisadores utilizam o enfoque indutivo na análise de seus dados. A pesquisa qualitativa trabalha com significados, motivos, valores, atitudes, processos e fenômenos que não podem ser trabalhados como variáveis. (GODOY, 1995, p. 58).

A entrevista aborda o envolvimento face a face entre pesquisador e pesquisado, em que um formula questões e o outro as responde. Conforme define Richardson (1999):

A entrevista semiestruturada observa os aspectos relevantes da pesquisa, visando obter informações detalhadas que possibilitem a realização de uma análise qualitativa, pois apresenta certa flexibilidade para o pesquisador em relação à situação e ao conteúdo apresentado pelo entrevistado.

A entrevista foi realizada nos meses de março e abril de 2013, com a presidenta da Associação, e essa escolha deve-se ao fato de que ela exerce um cargo representativo na Associação e está à frente das tomadas de decisões e atividades operacionais desde a sua fundação.

Além da entrevista, uma pesquisa de campo, com duração de três anos, também foi realizada pelo pesquisador, verificando as atividades de observação, identificação e análise dos dados até a obtenção dos resultados. Foi observada a evolução socioeconômica da RESOL, que apresentou progressão em seus indicadores de valor da renda dos associados, quantidade de novos postos de trabalho gerado e aumento na quantidade de material reciclado. Dados corroborados com as informações registradas durante a entrevista com a presidenta da Associação.

\section{Resultados e discussões}

\subsection{Perfil dos associados da RESOL}

A Associação é composta por 18 associados, sendo a maioria constituída por mulheres (em torno de 77,7\%). Conforme informações levantadas durante o período de observação em campo, a metade dos associados possui mais de 50 anos, e o principal motivo de ali trabalharem justifica-se pelo desemprego e ao fato de o mercado de trabalho não absorver a mão de obra de pessoas nessa faixa etária. A maioria é solteira, aproximadamente $70 \%$, e 
possuem 3 ou mais filhos. Em torno de $90 \%$ dos associados trabalhava anteriormente em algo que não estava relacionado à reciclagem, como, por exemplo: empregados domésticos, costureiras, serventes da construção civil, lavadores de carro e panfleteiros.

\subsection{Identificação e atividades realizadas pela Associação}

A RESOL (Imagem 1) é constituída legalmente como Associação, sendo Pessoa Jurídica de Direito Privado e com Cadastro Nacional de Pessoa Jurídica (CNPJ) desde 2002, data de sua fundação, cuja atividade-fim é a reciclagem de resíduos sólidos. Instituição sem fins lucrativos, cujo quadro associativo é composto exclusivamente por Catadores, tem por objetivo gerar trabalho e renda à comunidade local e a conservação do meio ambiente pelo incentivo da reciclagem, que reduz a quantidade de lixo enviada a aterros e lixões, ações estas voltadas à sustentabilidade socioeconômica e ambiental. Seus associados realizam atividades de coleta, triagem, prensagem, armazenagem e comercialização dos resíduos sólidos recicláveis.

A Associação é presidida pela Sra. Edna Freitas Menezes Martins, 51 anos, que é associada desde a fundação da instituição e realiza funções administrativas e treinamento operacional dos catadores, além de ser cozinheira, separadora de material reciclável e vendedora. Também representa os associados nas reuniões do Fórum Lixo e Cidadania, promovido pelo Ministério Público do Trabalho (MPT). Este Fórum tem por objetivo exigir os direitos legais e políticas públicas às associações e cooperativas de catadores das organizações públicas e privadas, visando ao fortalecimento da infraestrutura, como a reforma do barracão, equipamentos de reciclagem e doação dos materiais recicláveis (em cumprimento ao Decreto Federal no 5.940/2006).

Em 2010, houve uma parceria entre a Prefeitura Municipal de Colombo e a Empresa Brasileira de Agricultura e Pecuária (EMBRAPA), que cedeu gratuitamente em regime de comodato uma área de $10 \mathrm{mil} \mathrm{m}^{2}$.
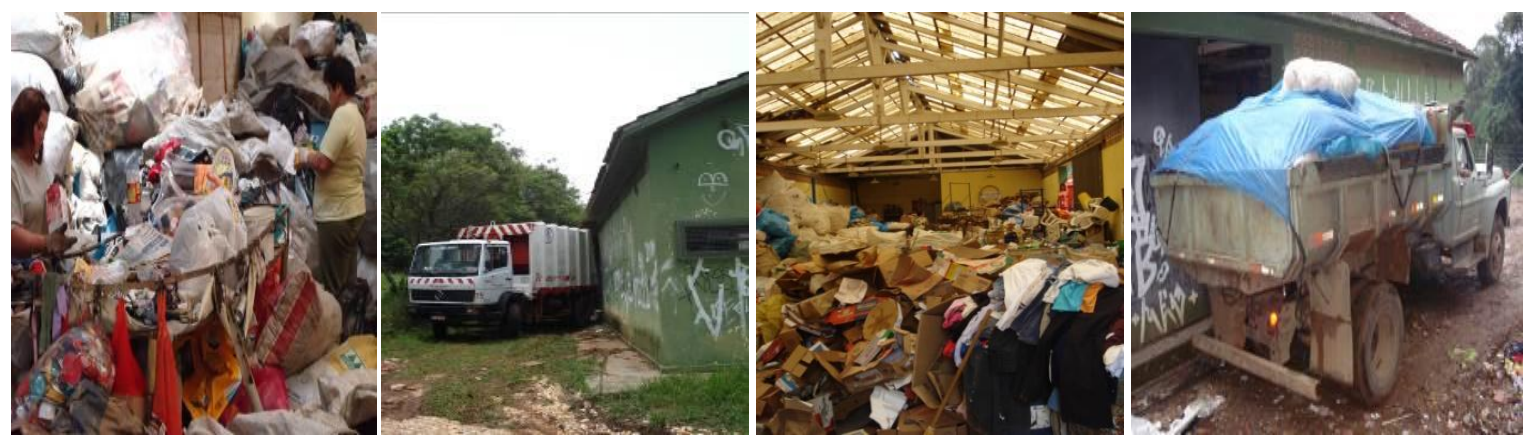

IMAGEM 1 - Infraestrutura da RESOL antes de receber os novos equipamentos

Fonte: Imagens de autoria do pesquisador. 
A atividade principal dos associados (Imagem 1) consiste na triagem dos materiais recicláveis e separação por tipos (metais, papel, papelão, vidro e plástico). Originalmente, a RESOL estava precariamente equipada, pois dispunha de poucos e velhos equipamentos para a triagem dos resíduos (duas mesas de separação de materiais, uma prensa e uma balança). Não havia eficiência no processo produtivo, o ambiente e layout eram desorganizados, havia acúmulo de materiais, tanto na chegada quanto na expedição, e decorrente falta de espaço no barracão. Devido à baixa produtividade da mão de obra, equipamentos sucateados e ineficiência logística, realizada por um caminhão impróprio à atividade da reciclagem, a qual necessita de transporte customizado a grandes volumes de materiais, o resultado financeiro era de prejuízo.

A reestruturação na infraestrutura da RESOL (Imagem 2) ocorreu em 2010, quando a FUNASA realizou um chamamento público, com o objetivo de selecionar projetos de cooperativas e associações voltadas diretamente às atividades de coleta e processamento de material reciclável. Para tanto, disponibilizou 24 milhões de reais do PAC/FUNASA, beneficiando 113 empreendimentos de catadores. A RESOL foi contemplada nesse Chamamento Público 002/2010, por meio da Proposta 101312/2010 do Projeto, no valor de 200 mil reais, que contemplou a aquisição de um caminhão baú e equipamentos para a reciclagem, como: esteira automática, prensa, balança digital e movimentador de fardos eletrônico.

A execução do projeto foi realizada de acordo com o valor do recurso aprovado, a análise e a escolha técnica do modelo de caminhão e carroceria baú, considerando a melhor eficiência logística e menor custo do produto e manutenção, e também pela análise e escolha técnica dos equipamentos, considerando o melhor custo-benefício, produtividade e segurança do trabalho.
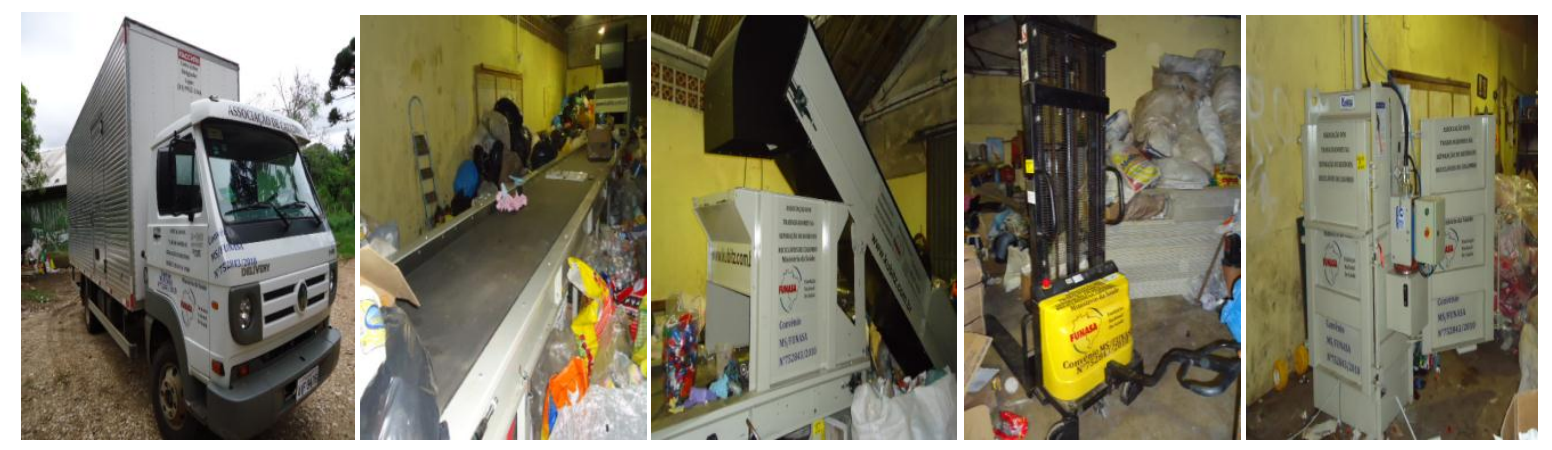

Imagem 2 - Infraestrutura da RESOL após os novos investimentos (equipamentos e caminhão)

Fonte: Imagens de autoria do pesquisador.

Conforme demonstrado na Imagem 2, foi adquirido um caminhão baú novo, com capacidade para 5 mil quilos, o suficiente para atender à necessidade logística de coleta e 
transporte do material acabado em forma de fardos para o comprador. O caminhão opera ininterruptamente, de segunda à sábado.

A esteira automática aumentou em $350 \%$ o rendimento na atividade de triagem/seleção dos materiais recicláveis quando comparado ao trabalho anteriormente realizado na mesa de triagem. O fato de ser automatizada dita o ritmo produtivo, pois é controlada eletronicamente de acordo com a prática e ritmo de trabalho dos associados. A esteira está acoplada modularmente a outro equipamento denominado talisca, o qual recepciona o material e, por meio de um funil, o distribui sobre a esteira, eliminando a necessidade de um associado ter que levantar o material e colocá-lo em cima da esteira evitando, consequentemente, lesões por esforço repetitivo (LER). O equipamento possui uma chave-geral de pânico, a qual desliga de imediato a esteira, se necessário, sendo um item relacionado à segurança do trabalho.

O elevador de fardos automático à bateria possibilita a mobilidade, deslocamento dos fardos e carregamento do caminhão. Esse equipamento tem capacidade de carga de até uma tonelada, sendo que os fardos podem ter massa de até 300 quilos. Essa atividade era realizada manualmente e causou muitos afastamentos por problemas musculares e de traumas.

A prensa tem capacidade de prensagem de até 18 toneladas, para fardos de 100 quilos, possui cinco dispositivos de travamento automático e uma chave de bloqueio geral, que minimiza o risco de acidentes de trabalho, pois, caso não seja seguido o procedimento de operação do fabricante, o equipamento não funciona.

A balança com display digital de alta precisão tem capacidade para até uma tonelada, além de saída eletrônica para computador e impressora, facilitando o registro do peso dos materiais enfardados.

Com a chegada dos novos equipamentos dotados de tecnologia de ponta, o processo produtivo aumentou sua eficiência e eficácia, e isso propiciou aumento da produtividade, segurança no trabalho, melhoria da renda e aumento de postos de trabalho para os associados.

\subsection{Identificação e análise dos materiais processados na RESOL}

O Gráfico 1 identifica a quantidade dos materiais: recebidos da coleta seletiva, coletado nas instituições doadoras (papel e plástico), triados por tipo da composição material (vidro, metal, plástico e papel) e rejeitos (orgânicos e lixo comum), durante os meses de janeiro a dezembro de 2012 na RESOL. 


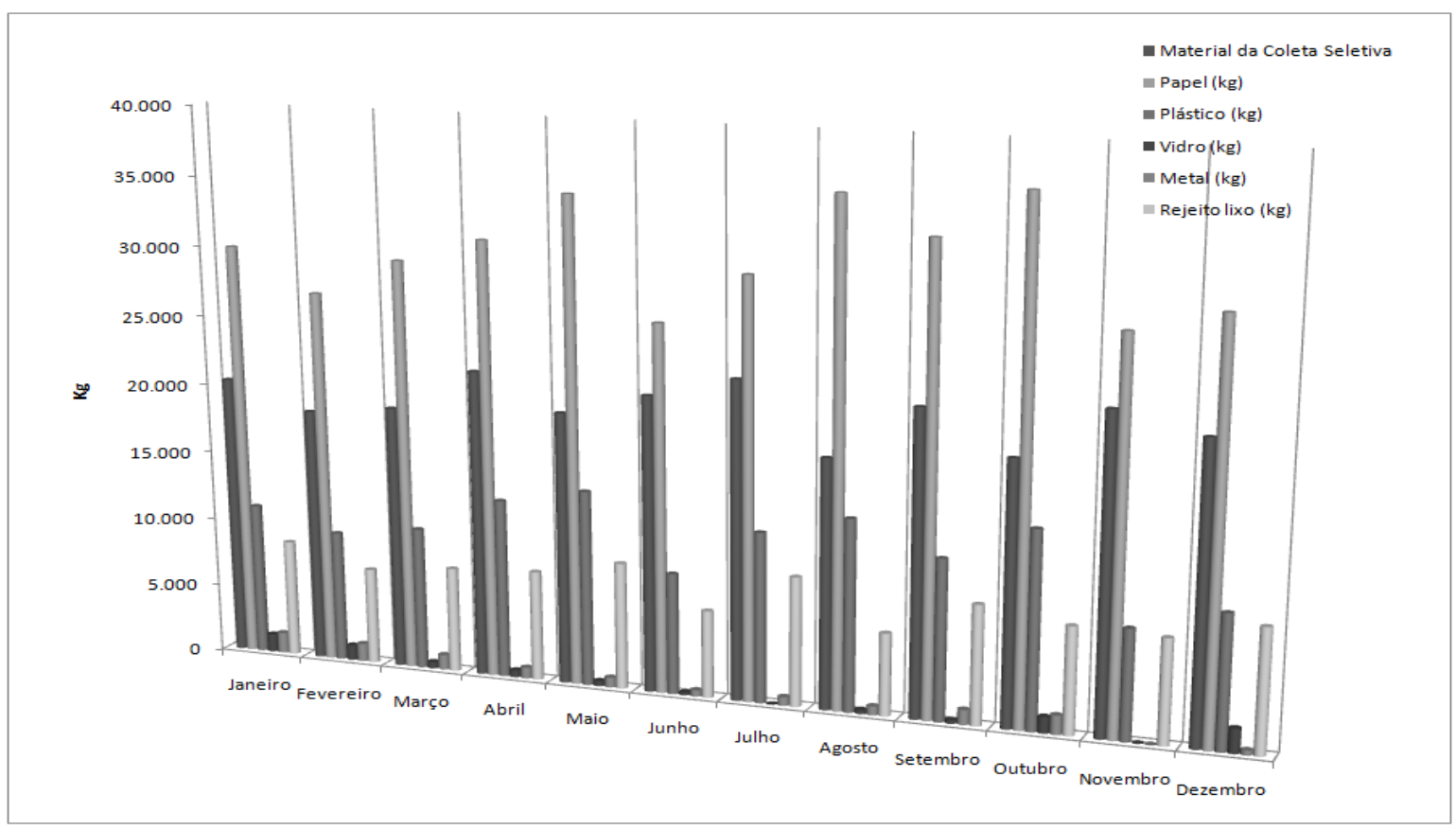

GRÁFICO 1 - Quantidade (em Kg) de materiais triados por tipo pela RESOL em 2012 provenientes da coleta seletiva e doações

Fonte: Elaborado pelo autor conforme dados fornecidos pela presidente da RESOL.

Analisando o Gráfico 1, é possível constatar que, em 2012, a RESOL recebeu 623.175 kg/ano de resíduos sólidos, provenientes da coleta seletiva e das doações de parceiros, um aumento de 217,97\% quando comparado à quantidade recebida em 2011. Desse total, foram reciclados $528.015 \mathrm{~kg} / \mathrm{ano}$, ou seja, 276,80\% a mais que no ano de 2011. Quanto ao material proveniente da coleta seletiva $(247.300 \mathrm{~kg} / \mathrm{ano})$, aproximadamente $38,47 \%$ do material foi rejeitado, o que corresponde a $95.160 \mathrm{~kg}$ de lixo descartado para o aterro sanitário. Esse índice melhorou quando comparado ao ano de 2011 , em que $50 \%$ do material da coleta seletiva foi rejeitado.

Conforme relatado pela presidenta, "o povo mistura o lixo orgânico aos materiais recicláveis, além de não lavar as embalagens, que são enviadas com o resto de comida, e por isso precisam ser descartadas durante a triagem". Ela percebe que menos materiais serão rejeitados quando houver conscientização das pessoas e investimentos em educação ambiental, todavia, outros materiais são rejeitados por não haver compradores, como: bandejas de isopor, plásticos filme de radiografia, garrafas long neck, laminados (salgadinho e suco) e espuma.

Conforme ilustrado no Gráfico 1, o papel/papelão é o material mais comercializado. Esse indicador foi influenciado pela coleta feita com o novo caminhão, que os recolhe em grande quantidade dos supermercados e comércio local, o que representou $373.700 \mathrm{~kg}$ de papelão coletado em 2012. Outro material doado e que tem bom valor de comercialização é o plástico, sendo o segundo material em volume de vendas (136.770 kg/ano). 


\subsection{Entrevista com a presidenta da RESOL}

A entrevista realizada com a presidenta da RESOL ressalta a importância da execução do projeto para equipar a Associação e a evolução quanto ao desenvolvimento das atividades de coleta, triagem e comercialização dos materiais, tendo como consequência o aumento da renda, geração de novos postos de trabalho e desenvolvimento da comunidade local.

Na opinião da presidenta da RESOL, Sra. Edna Freitas, conforme transcrição ipsis litteris da entrevista, a Associação tem influência preponderante na vida dos associados e de seus familiares:

Nós trabalha pra deixar a vida melhor pros associados e nossos filhos, netos e parentes, graças ao dinheirinho que entra na venda do material. Muita gente que trabalha aqui ganha pro seu sustento e até sobra pra comprar umas roupas lá no bazar da igreja, e também pra pagar a conta da luz, água e aluguel. Porque antes de trabalhar na RESOL, a maioria do povo passava fome ou ficava mendigando na vila. Aqui a maioria dos associados é mulher, que foram abandonadas pelo marido e ficaram com os filhos pra criar.

Quando questionada sobre a mudança do cenário de como era a RESOL antes e a transformação após os investimentos em equipamentos e caminhão, proporcionado pelo projeto englobado pelas políticas públicas do governo federal, por meio da FUNASA, como apoio às Associações de Catadores, a presidenta tem a seguinte opinião:

Foi uma benção a chegada do caminhão novo e dos equipamentos pra separação e prensagem dos materiais. Antes a gente não tinha nem uma mesa que prestasse pra separar os materiais, a prensa vivia dando problema e a gente dependia da vinda do caminhão da prefeitura da coleta seletiva, ou do caminhão velho do Chico, que cobrava aluguel pra trazer o material doado. Depois que o rapaz do mestrado do Cefet fez o Projeto com o governo e correu atrás da instalação dos equipamentos e compra do caminhão, nossa vida melhorou. Agora a gente ganha mais e também tem mais vagas de trabalho na Associação. Tá todo mundo feliz e motivado a trabalhar, pois estamos vendo os resultados acontecer.

Em relação aos planos futuros da RESOL, a presidenta tem a seguinte opinião:

A gente quer aumentar o barracão pra dar mais vagas pras pessoas daqui da vila, principalmente pros jovens maiores de 18 anos, que ficam o dia inteiro sem fazer nada na rua e, pior, aprontando por aí, eles precisam de uma ocupação, e é pra isto que vamos trabalhar. 


\subsection{Identificação e análise da evolução da renda e dos postos de trabalho na Associação}

Foi realizado o acompanhamento em campo da RESOL durante um período de três anos. Em um diário, foram registradas as informações que serviriam de base à elaboração da pesquisa, aliadas às informações transmitidas pela presidenta.

Quanto ao aumento da renda média mensal, o Gráfico 2 identifica e compara o ano de 2011 com a evolução da renda nos anos de 2012 e 2013, agregada à vinda dos novos equipamentos e caminhão na RESOL:

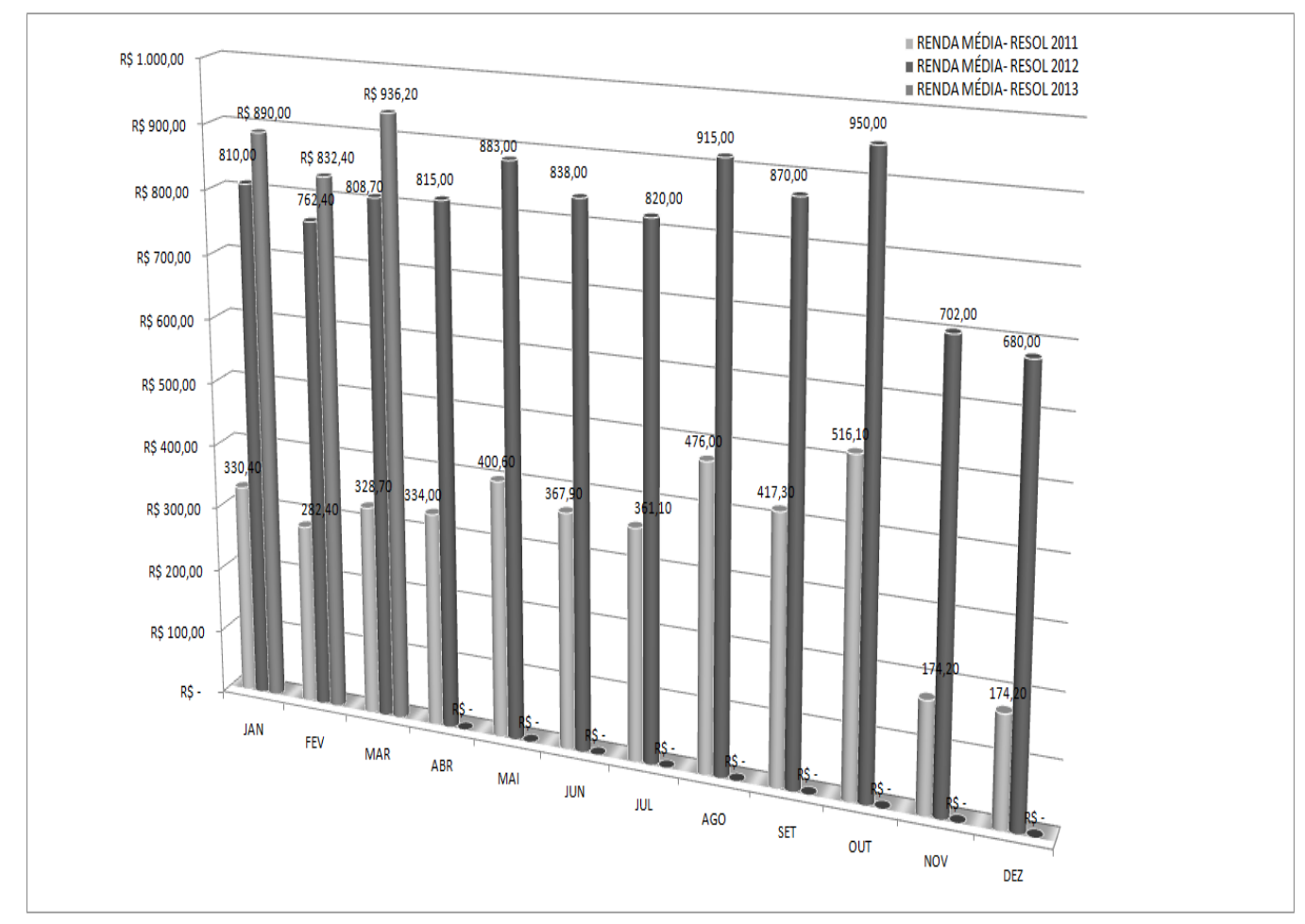

GRÁFICO 2 - Evolução da renda média dos associados da RESOL em 2011, 2012 e 2013, a partir da vinda dos novos equipamentos e caminhão à coleta de materiais doados por parceiros.

Fonte: Elaborado pelo pesquisador conforme dados recebidos da presidenta da RESOL.

Analisando o Gráfico 2, é possível constatar que houve aumento da renda dos catadores de $285 \%$, dentre o período compreendido entre 2012 até março de 2013, quando comparado à renda média do ano de 2011. Atribui-se essa evolução à: geração de oito novos postos de trabalho que processam mais materiais, um aumento de $80 \%$ quando comparado ao período antes da chegada dos novos equipamentos; implementação dos novos equipamentos (esteira, prensa, entre outros); vinda do caminhão novo, doado pela FUNASA, complementando com o início das operações logísticas ordenadas de coleta de materiais doados pelos parceiros (supermercados, empresas e condomínios). Esses materiais (papelões e plásticos do tipo cristal) são de melhor qualidade e têm maior valor de venda, por serem 
limpos, quando comparados aos materiais recebidos da coleta seletiva, que são sujos e de baixa qualidade.

Verifica-se que a renda de $\mathrm{R} \$ 328,70$, em março de 2011 , aumentou para $\mathrm{R} \$ 936,20$, sendo que durante esse período não houve aumento do valor pago na venda dos materiais pelo atravessador (comprador).

O Gráfico 2 apresenta alguns picos no aumento da renda, em contrapartida, há também certa redução, fato que pode ser atribuído ao período de sazonalidade na venda dos materiais, no período compreendido entre os meses de novembro e dezembro, quando o atravessador paga um valor menor pelo material, justificando que a indústria final que compra o material e processa a reciclagem fica em recesso coletivo no fim de ano, acarretando aumento dos estoques de recicláveis. Dessa forma, as associações são obrigadas a vender o material por um preço menor.

\section{Conclusão}

A partir do estudo de caso apresentado, houve a identificação e análise da associação de catadores de materiais recicláveis, situada na região metropolitana de Curitiba, e realizada a contextualização da RESOL, por meio da observação de seu processo de desenvolvimento e sustentabilidade socioeconômica e ambiental.

Quanto ao processo de desenvolvimento da sustentabilidade, destaca-se: o desenvolvimento social, associado à inclusão do trabalho dos catadores, oportunizando o desenvolvimento da atividade da reciclagem por meio de uma entidade organizada; o resgate da cidadania e a intenção de justiça social, pela oportunidade de ter um trabalho e, consequentemente, uma renda mensal, mesmo que ainda bastante reduzida; o resgate social de um cenário de miserabilidade para o mercado de trabalho. A questão de gênero é observada, uma vez que a maioria dos associados é composta por mulheres.

A questão do desenvolvimento econômico configura-se pela geração de renda proveniente da atividade, trazendo os atores para a condição de economicamente ativos. Há políticas públicas de apoio aos empreendimentos dos catadores. Nesse cenário, a RESOL foi contemplada pelo projeto de fortalecimento estrutural com equipamentos de reciclagem e logística, por meio da FUNASA.

O desenvolvimento ambiental é observado no trabalho realizado pelos catadores associados para a promoção de uma maior conservação ambiental, que ocorre por causa da reciclagem, resultado do reaproveitamento da matéria-prima. No ano de 2012, foram reciclados $528.015 \mathrm{~kg}$, um aumento de $276,80 \%$ em comparação a 2011. Esse material era anteriormente descartado pela sociedade em aterros e lixões, gerando poluição do meio ambiente.

Com o início das coletas feitas pelo novo caminhão e a implementação dos novos equipamentos no processo produtivo houve melhora da eficácia, resultando no aumento da 
renda dos catadores em aproximadamente $285 \%$ na média de 2012 a 2013, quando comparada ao mesmo período do ano de 2011. Dessa forma, a tendência da RESOL é evoluir gradativamente no cumprimento de sua função social, que é a criação e o aumento de postos de trabalho, geração de renda para os catadores e consequente desenvolvimento local.

\section{REFERÊNCIAS}

BRASIL. Constituição (1988). Constituição da República Federativa do Brasil. Brasília, DF: Senado Federal, 1998.

CASAGRANDE JUNIOR, Eloy Fassi. Apostila da Disciplina Desenvolvimento Tecnológico Sustentável. Programa de Pós-Graduação em Tecnologia - PPGTE. Curitiba: CEFET, 2001. 50 p.

CEMPRE. Compromisso Empresarial para Reciclagem. Disponível em <http://www.cempre.org.br>. Acesso em: 30 jul. 2013.

GODOY, Arilda Schmidt. Introdução à pesquisa qualitativa e suas possibilidades. Revista de Administração de Empresas, v. 35, n. 2, p. 57-63. 1995.

GUARESCHI, Neuza et al. Problematizando as práticas psicológicas no modo de entender a violência. In: STREY, Marlene Neves; AZAMBUJA, Mariana Porto Ruwer de; JAEGER, Fernanda Pires (Org.). Violência, gênero e políticas públicas. Porto Alegre: EDIPUCRS, 2004. p. 177-194.

JACOBI, Pedro. Meio ambiente urbano e sustentabilidade: alguns elementos para a reflexão. In: CAVAlCANTI, Clovis (Org.). Meio Ambiente, Desenvolvimento Sustentável e Políticas Públicas. São Paulo: Cortez, 1997.

RAZZOTO, Evandro. Eco Sustentabilidade: dicas para tornar você e sua empresa sustentável. Curitiba: Gráfica Absoluta, 2009.

RICHARDSON, Roberto Jerry. Pesquisa Social. São Paulo: Atlas, 1999.

SEN, Amartya K. Desenvolvimento como Liberdade. São Paulo: Companhia das Letras, 1999. 